\title{
Decreased Expression of Transient Receptor Potential Vanilloid 1 Impairs the Postischemic Recovery of Diabetic Mouse Hearts
}

\author{
Zhonghai Wei, MM*,†; Lihong Wang, $\mathrm{PhD}, \mathrm{MD}^{\dagger}$; Jie Han, MM; Junxian Song, MM; \\ Lei Yao, MD**; Lei Shao, MM; Zhihui Sun, MM; Liangrong Zheng, MD
}

\begin{abstract}
Background: We hypothesized that the transient receptor potential vanilloid type 1 (TRPV1), which is found in the sensory nerve fibers, could modulate the cardiac function, be impaired by diabetes and could contribute to further severe postischemic heart injury.

Methods and Results: Diabetes was induced in ICR mice by an intraperitoneal injection of streptozotocin. The expression of both TRPV1 and calcitonin gene-related peptide (CGRP) in diabetes mellitus (DM) hearts was significantly lower, as determined by Western blot and radioimmunoassay, respectively. During the ischemia/reperfusion, the cardiac function was measured by a Medlab system and the lactate dehydrogenase (LDH) in the effluents was measured by an ELISA kit. Compared with the non-DM hearts, the DM hearts demonstrated increased left ventricular end-diastolic pressure and decreased left ventricular developed pressure, heart rate and coronary flow, and also released more LDH in the effluents. Pretreatment with capsaicin attenuated the postischemic injury significantly in non-DM hearts, but not in DM hearts. Pretreatment with CGRP in both non-DM and DM hearts protected hearts against ischemic injury.
\end{abstract}

Conclusions: The alteration of TRPV1 caused by diabetes is related to the poor recovery of cardiac function after myocardial ischemia. (Circ J 2009; 73: 1127-1132)

Key Words: Diabetes mellitus; Mouse; Postischemic injury; TRPV1

D iabetes mellitus (DM) is one of the most important risk factors of cardiovascular diseases, and numerous patients who are afflicted with diabetes usually suffer the diffused stenosis of coronary arteries, leading to dreadful consequences such as myocardial infarction and cardiomyopathy. Non-invasive evaluation tools such as Doppler echocardiography demonstrate the impairment of cardiac function in diabetic animal models as well as in diabetic patients 1,2 whereas the mechanism is still not well elucidated.

Neuropathy is one of the common complications of diabetes, which could result in the degeneration of the nerve fibers both in diabetic animals and patients $3^{3-5}$ Transient Receptor Potential Vanilloid 1 (TRPV1) is a non-selective cation channel and is diversely distributed in terminals of sensory nerve fibers, dorsal root ganglia (DRG), spinal cord, and many other various regions in the brain? It could lead to the release of neurotransmitters such as calcitonin gene-

(Received October 9, 2008; revised manuscript received January 17, 2009; accepted January 18, 2009; released online April 17, 2009)

Department of Cardiovascular Sciences, The First Affiliated Hospital, College of Medicine, Zhejiang University, Hangzhou, Zhejiang, *Department of Medicine, The Affiliated DrumTower Hospital, Nanjing University Medical School, Nanjing, Jiangsu and **Department of Ultrasound, The First Affiliated Hospital, College of Medicine, Zhejiang University, Hangzhou, Zhejiang, China

$\dagger$ The first two authors contributed equally to this work.

Mailing address: Liangrong Zheng, MD, Department of Cardiovascular Sciences, The First Affiliated Hospital, College of Medicine, Zhejiang University, Hangzhou, Zhejiang 310003, China. E-mail: zlrylnn@126.com

All rights are reserved to the Japanese Circulation Society. For permissions, please e-mail: cj@j-circ.or.jp related peptide (CGRP) from peripheral nerve terminals when activated by capsaicin, protons, noxious heat, etc?,8 It has been found that in diabetes-prone NOD mice, the protein expression and function of TRPV1 was significantly depressed in DRG? Using immunohistochemical staining, TRPV1 was also found to be reduced in epineurial arterioles in long-term diabetic rats! ${ }^{10}$ These investigations suggest that the expression of TRPV1 is susceptible to diabetes. In addition, recent studies disclose that TRPV1 is expressed in the myocardium and perivascular region, which are close to the epicardial surface of ventricles ${ }^{11}$ We revealed that the expression of TRPV1 in diabetic hearts was significantly suppressed in our previous study $!^{2}$ However, the impact of the decreased TRPV1 on the diabetic heart has not been investigated yet.

A few studies have revealed that TRPV1 can serve as a molecular integrator of various noxious stimuli, especially the myocardial ischemia, in order to protect the hearts against ischemic injury!11,13 For example, exogenous agonists of TRPV1 exert a cardioprotective effect on ischemia/reperfusion injury, whereas TRPV1 gene knockout eliminates the protection ${ }^{14,15}$ Therefore, it is reasonable to hypothesize that the alteration of TRPV1 secondary to diabetes can be related to the severe postischemic injury of the heart.

In the present study, we measure the expression of TRPV1 and CGRP in diabetic hearts and investigate the effect of TRPV1 on the cardiac function after ischemia injury. The results might help explain the vulnerability of diabetic hearts to ischemic injury. 
Table 1. Plasma Glucose Levels of the Mice Used for Western Blot and Radioimmunoassay Before and After Injection of STZ

\begin{tabular}{lcc}
\hline & \multicolumn{2}{c}{ Plasma glucose (mmol/L) } \\
\cline { 2 - 3 } & Non-DM $(\mathrm{n}=11)$ & $\mathrm{DM}(\mathrm{n}=11)$ \\
\hline Before injection & $4.82 \pm 0.20$ & $4.40 \pm 0.25$ \\
3 days after injection & $4.82 \pm 0.15$ & $26.18 \pm 1.29^{*}$ \\
8 weeks after injection & $4.79 \pm 0.17$ & $27.19 \pm 1.10^{*}$ \\
\hline
\end{tabular}

Values are mean \pm SEM.

$* \mathrm{P}<0.01$, compared with non-DM group.

STZ, streptozotocin; DM, diabetes mellitus.

\section{Methods}

\section{Animal Preparation}

Male ICR mice, weighing 18-22g, were obtained from the Shanghai Laboratory Animal Center of the Chinese Academy of Sciences, and were housed in the animal facility, which was maintained at $20-25^{\circ} \mathrm{C}, 55 \%$ relative humidity, and with an automatic 12-h light/dark cycle. All mice were allowed to acclimatise for 1 week before the experiments started and received a standard laboratory diet and tap water ad libitum. The surgical procedures were approved by the Institutional Council for Animal Research, Zhejiang University, and conformed to the Guide for the Care and Use of Laboratory Animals published by the US National Institutes of Health (NIH Publication No. 85-23, revised 1996).

\section{Induction of DM}

Mice were injected intraperitoneally with either $150 \mathrm{mg} / \mathrm{kg}$ of streptozotocin (STZ) (Sigma) dissolved in $0.1 \mathrm{~mol} / \mathrm{L}$ citrate buffer $(\mathrm{pH} 4.5)$ or with an equivalent volume of citrate buffer solution after fasting for $6 \mathrm{~h}$. Blood glucose was measured by nipping the distal part of the tail during a fasting state at 3 days and 8 weeks post-STZ injection using the OneTouch SureStep blood glucose monitoring system (LifeScan). The plasma glucose concentration of $\geq 16.7 \mathrm{mmol} / \mathrm{L}$ at 3 days and 8 weeks was the criterion for experimental DM.

\section{Western Blot}

Membrane protein of the whole heart was extracted according to the method described previously ${ }^{16}$ and the protein concentration was determined using the Bradford method. The $25 \mu \mathrm{g}$ of protein was electrophoresed, and transferred onto polyvinylidene fluoride membranes. Thereafter, the membranes were incubated with goat anti-rat TRPV1 primary antibody (1:500 dilution, Santa Cruz, CA, USA) and donkey anti-goat IgG-HRP second antibody (1:4,000 dilution, Santa Cruz) in succession. Finally, they were incubated with EZ-ECL (Biological Industries, Haemek, Israel) and exposed to film. The blots were semiquantified using Quantity One imaging software (Bio-Rad) and corrected in comparison with glyceraldehyde-3-phosphate dehydrogenase (GAPDH).

\section{Radioimmunoassay}

The hearts were soaked in $1 \mathrm{ml}$ of $0.5 \mathrm{~mol} / \mathrm{L}$ acetic acid, then boiled and centrifuged. The supernatants were preserved for measurement of CGRP with a rabbit anti-rat CGRP radioimmunoassay kit (Furui Biological Engineering, Beijing, China). The results were normalized for the heart weights.

\section{Measurement of Cardiac Function}

The hearts were cannulated on the Langendorff apparatus system and perfused with the Krebs-Henseleit buffer $(\mathrm{NaCl}$ $118 \mathrm{mmol} / \mathrm{L}, \mathrm{KCl} 4.7 \mathrm{mmo} / \mathrm{L}, \mathrm{MgSO}_{4} 1.2 \mathrm{mmol} / \mathrm{L}, \mathrm{KH}_{2} \mathrm{PO} 4$ $1.2 \mathrm{mmol} / \mathrm{L}, \mathrm{CaCl}_{2} 2.5 \mathrm{mmol} / \mathrm{L}, \mathrm{NaHCO}_{3} 2.5 \mathrm{mmol} / \mathrm{L}, \mathrm{Na}-$ EDTA $0.5 \mathrm{mmol} / \mathrm{L}$, glucose $11 \mathrm{mmol} / \mathrm{L}, \mathrm{pH} 7.4$, saturated with $95 \% \mathrm{O}_{2}$ and $5 \% \mathrm{CO}_{2}$ ) retrogradely from the aortic root. A water-filled balloon was set up, which was connected to the Medlab 6.0 system (Nanjing Meiyi Science and Technology Co Ltd, Nanjing, China) through the catheter and pressure transducer. The balloon was inserted into the left ventricle and the left ventricular end-diastolic pressure (LVEDP) was adjusted to between 5 and $8 \mathrm{mmHg}$ through controlling the balloon volume so that the Medlab system was able to measure the heart function precisely. The parameters of cardiac function at the end of reperfusion were collected and analyzed.

\section{Experimental Protocols}

The mice were randomized into 6 groups, and 3 groups were induced to have diabetes while the other 3 groups served as the controls. The isolated hearts from the thoracic cavity were stabilized for $30 \mathrm{~min}$ after they were fixed on the Langendorff apparatus. All hearts were subject to the noflow normothemic global ischemia. The animal assignments and treatments are detailed as follows:

Group 1 (Non-DM hearts) The hearts were imposed on $30 \mathrm{~min}$ of ischemia, followed by $40 \mathrm{~min}$ of reperfusion without any drugs.

Group 2 (Non-DM hearts + Capsaicin) The hearts were exposed to Capsaicin $\left(10^{-6} \mathrm{~mol} / \mathrm{L}\right)$ (Sigma) for $5 \mathrm{~min}$ before ischemia 17 then subjected to $30 \mathrm{~min}$ of ischemia and $40 \mathrm{~min}$ of reperfusion ensued.

Group 3 (Non-DM hearts + CGRP) The hearts were pretreated with the perfusate containing CGRP $\left(10^{-7} \mathrm{mmol} / \mathrm{L}\right)$ (Sigma) for $5 \mathrm{~min}$ in advance, ${ }^{15}$ then underwent ischemia for $30 \mathrm{~min}$, which was followed by reperfusion for $40 \mathrm{~min}$.

Group 4 (DM hearts) The hearts were isolated from diabetic mice and treated the same as that of group 1.

Group 5 (DM hearts + Capsaicin) The hearts were isolated from diabetic mice and the treatment was the same as that of group 2.

Group 6 (DM hearts + CGRP) The hearts were isolated from diabetic mice and the treatment was the same as that of group 3.

\section{Measurement of the LDH}

The severity of myocardial injury was determined by the concentration of lactate dehydrogenase (LDH) in the effluent. The effluents during the whole 40-min reperfusion were collected from all groups and the concentration of $\mathrm{LDH}$ was assayed using a LDH ELISA kit (ADL). The concentration of LDH in the effluent during the 40-min reperfusion was normalized for the wet weight of the heart.

\section{Statistical Analysis}

All results are mean \pm SEM. The differences among the groups were determined by one-way ANOVA, and the difference between means was further identified with the least significant difference test (LSD) if a statistical difference was detected in the ANOVA analysis. A $\mathrm{P}<0.05$ was considered statistically significant. 
Table 2. Plasma Glucose Levels of the Mice Used for Ischemia/Reperfusion Before and After Injection of STZ

\begin{tabular}{lcccccc}
\hline & \multicolumn{7}{c}{ Plasma glucose (mmol/L) } \\
\cline { 2 - 6 } & $\begin{array}{c}\text { Group 1 } \\
(\mathrm{n}=9)\end{array}$ & $\begin{array}{c}\text { Group 2 } \\
(\mathrm{n}=8)\end{array}$ & $\begin{array}{c}\text { Group 3 } \\
(\mathrm{n}=8)\end{array}$ & $\begin{array}{c}\text { Group 4 } \\
(\mathrm{n}=8)\end{array}$ & $\begin{array}{c}\text { Group 5 } \\
(\mathrm{n}=9)\end{array}$ & $\begin{array}{c}\text { Group 6 } \\
(\mathrm{n}=10)\end{array}$ \\
\hline Before injection & $5.05 \pm 0.26$ & $4.58 \pm 0.25$ & $5.14 \pm 0.27$ & $4.94 \pm 0.32$ & $4.74 \pm 0.29$ & $4.91 \pm 0.18$ \\
3 days after injection & $4.87 \pm 0.28$ & $4.88 \pm 0.26$ & $4.99 \pm 0.27$ & $24.59 \pm 1.78^{*}$ & $27.81 \pm 1.22^{\dagger}$ & $26.29 \pm 1.22^{\ddagger}$ \\
8 weeks after injection & $5.00 \pm 0.29$ & $4.61 \pm 0.27$ & $5.08 \pm 0.25$ & $25.95 \pm 1.77^{*}$ & $26.22 \pm 1.48^{\dagger}$ & $24.66 \pm 1.50^{\ddagger}$ \\
\hline
\end{tabular}

Values are mean \pm SEM.

*P $<0.01$, compared with group $1 ;{ }^{\dagger} \mathrm{P}<0.01$, compared with group 2 ; ${ }^{\star} \mathrm{P}<0.01$, compared with group 3 .

STZ, streptozotocin.
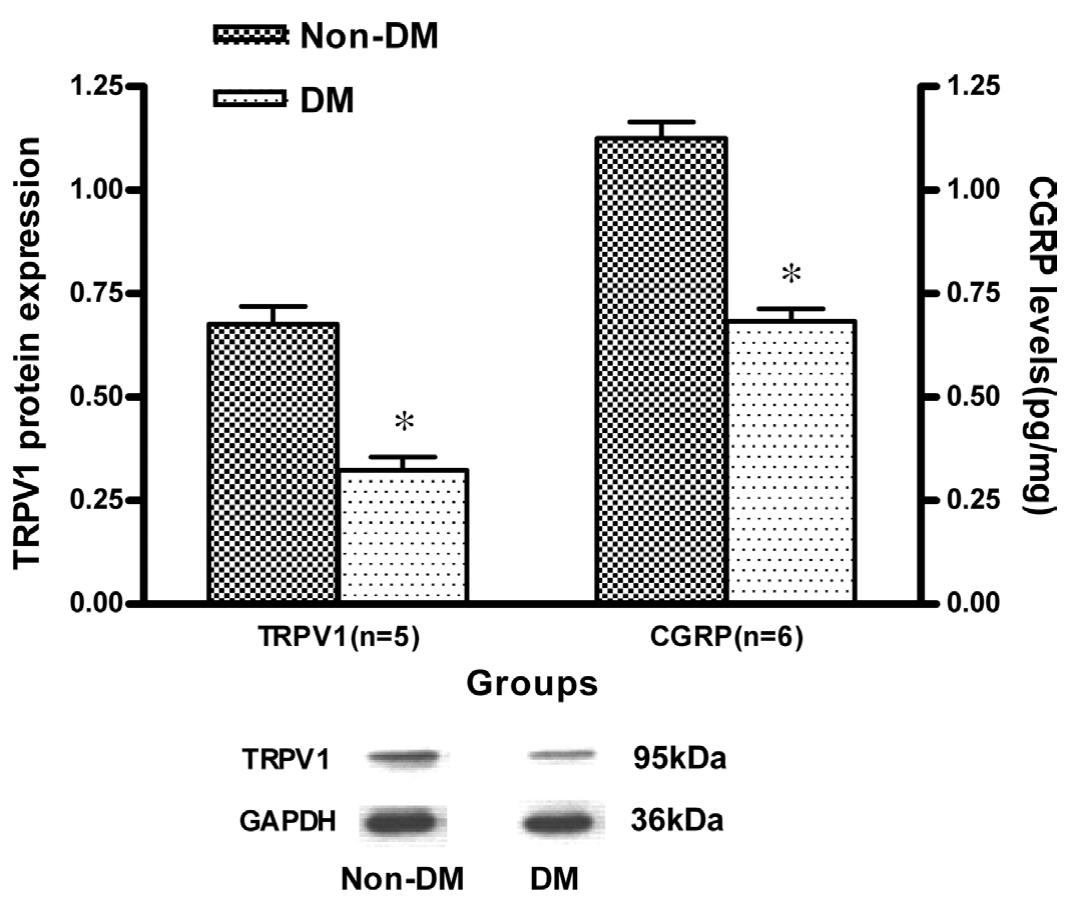

Figure 1. Expression of the transient receptor potential vanilloid type 1 (TRPV1) protein and calcitonin gene-related peptide (CGRP) level in non-diabetes mellitus (DM) and DM heart tissues. Western blot bands for TRPV1 and glyceraldehyde-3-phosphate dehydrogenase (GAPDH) are shown. The expression of TRPV1 and CGRP in the DM hearts were both suppressed significantly compared with that in non-DM hearts. Values are expressed as mean $\pm \mathrm{SEM} ; * \mathrm{P}<0.01$, compared with the non-DM group.

\section{Results}

\section{Plasma Glucose}

The plasma glucose levels of the mice used for Western blot and radioimmunoassay are shown in Table 1. The plasma glucose level of the DM mice was significantly higher than that of the non-DM mice both at 3 days and 8 weeks after the injection of STZ $(\mathrm{P}<0.01)$. The plasma glucose level of the mice used for the ischemia/reperfusion is shown in Table 2, and at 3 days and 8 weeks of STZ injection, the plasma glucose levels in groups 4, 5 and 6 were significantly higher than those of the non-DM mice in groups 1,2 and 3 , respectively $(\mathrm{P}<0.01)$, while no significant difference was observed within the 3 non-DM groups as well as within the 3 DM groups.

\section{Expression of TRPV1 and CGRP}

The expression of TRPV1 and CGRP in the DM hearts was significantly lower than that in the non-DM hearts $(\mathrm{P}<$ 0.01) (Figure 1), which is consistent with our previous study, 12 suggesting that the expression of TRPV1 and CGRP was remarkably suppressed in diabetic hearts.

\section{Cardiac Function}

The values used for the assessment of cardiac function, which were obtained at the end of the 40-min reperfusion, are shown in Figures 2-5. Compared with the non-DM hearts, the DM hearts had higher LVEDP and lower left ventricular diastolic pressure (LVDP), HR and CF, which were statistically significant $(\mathrm{P}<0.05)$. The results indicate that the DM hearts suffered the more severe impairment of cardiac function after the ischemic/reperfusion as compared with the non-DM hearts.

Furthermore, the pretreatment of the non-DM hearts with capsaicin pronouncedly decreased the LVEDP and increased the LVDP, HR and CF compared with the untreated nonDM hearts $(\mathrm{P}<0.05)$. Whereas capsaicin did not exert the similar protective effect on the DM hearts, implying that the cardioprotective effect of exogenous capsaicin was jeopardized in the DM hearts. Namely, it could be inferred that the loss of TRPV1 partially led to the consequent conditions in the diabetic hearts.

However, the pretreatment with CGRP significantly decreased the LVEDP and increased the LVDP, HR and $\mathrm{CF}$ in both non-DM and DM hearts compared with the corresponding untreated hearts, respectively $(\mathrm{P}<0.05)$, demonstrating that the protective role of exogenous CGRP against ischemic injury was preserved in the DM hearts as in the non-DM hearts.

\section{Myocardial Injury}

The concentration of LDH in the effluent released from 


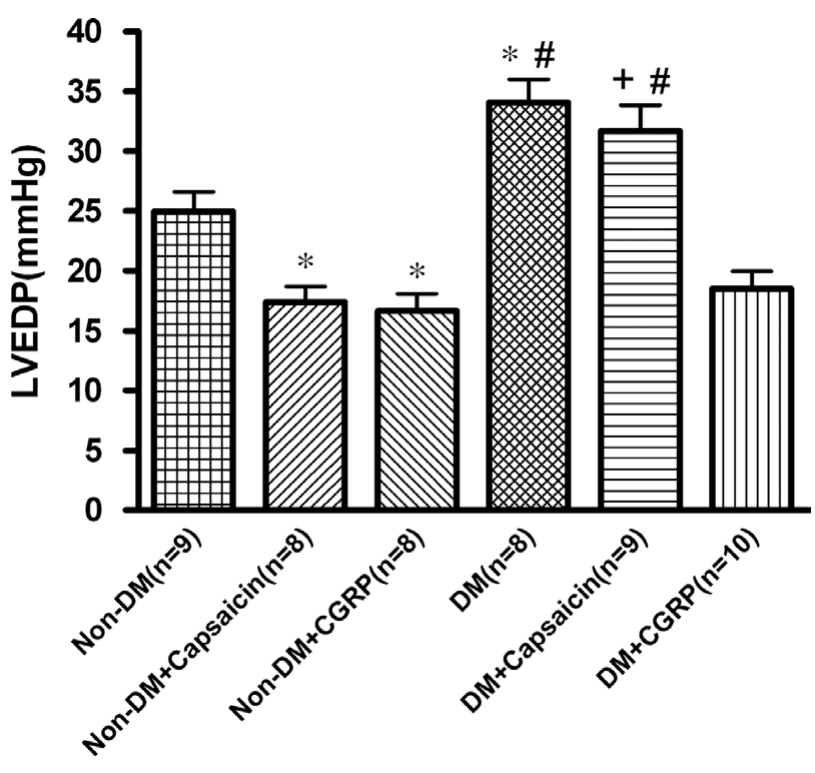

Groups

Figure 2. Effects of capsaicin pretreatment and calcitonin generelated peptide (CGRP) on the left ventricular end-diastolic pressure (LVEDP) of the diabetic hearts at the end of a 40-min reperfusion. The capsaicin was not able to decrease the LVEDP in diabetes mellitus (DM) hearts just as it did in non-DM hearts, while the CGRP could decrease the LVEDP in both DM and non-DM hearts. Values are mean \pm SEM; $* \mathrm{P}<0.01$, compared with the non-DM group. ${ }^{+} \mathrm{P}<0.01$, compared with the non-DM+Capsaicin group. ${ }^{\#} \mathrm{P}<0.01$, compared with the DM+CGRP group.

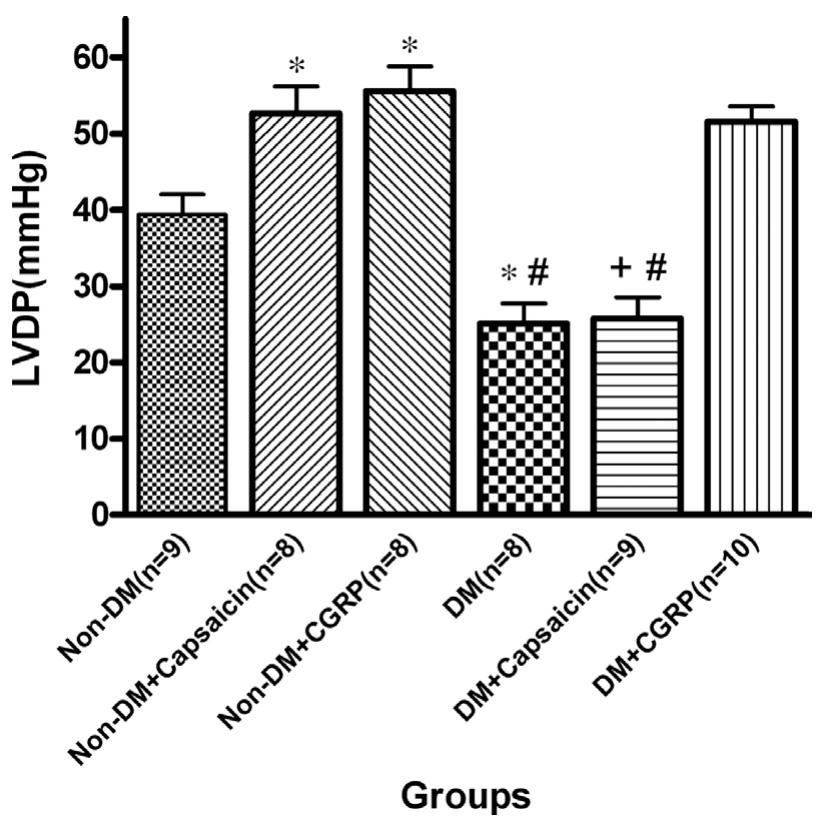

Figure 3. Effects of capsaicin pretreatment and calcitonin generelated peptide (CGRP) on the left ventricular diastolic pressure (LVDP) of the diabetic hearts at the end of a 40-min reperfusion. The capsaicin could not increase the LVDP in diabetes mellitus (DM) hearts just as it did in non-DM hearts, while the CGRP increased the LVDP in both DM and non-DM hearts. Values are mean \pm SEM; $* \mathrm{P}<$ 0.01 , compared with the non-DM group. ${ }^{+} \mathrm{P}<0.01$, compared with the non-DM+Capsaicin group. ${ }^{\#}<0.01$, compared with the DM+CGRP group.

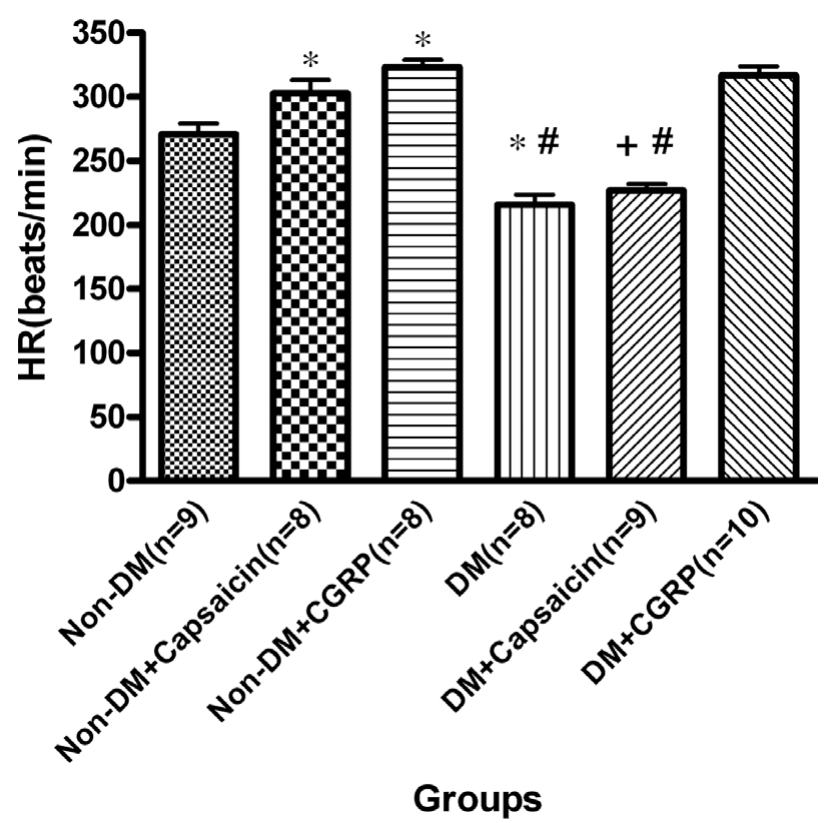

Figure 4. Effects of capsaicin pretreatment and calcitonin generelated peptide (CGRP) on the HR of the diabetic hearts at the end of a 40-min reperfusion. The capsaicin did not increase the heart rate in diabetes mellitus (DM) hearts just as it did in non-DM hearts. In contrast, the CGRP could increase the heart rate in both DM and non-DM hearts. Values are mean \pm SEM; ${ }^{*} \mathrm{P}<0.01$, compared with the non-DM group. ${ }^{+} \mathrm{P}<0.01$, compared with the non-DM+Capsaicin group. ${ }^{\#} \mathrm{P}<$ 0.01 , compared with the DM+CGRP group.

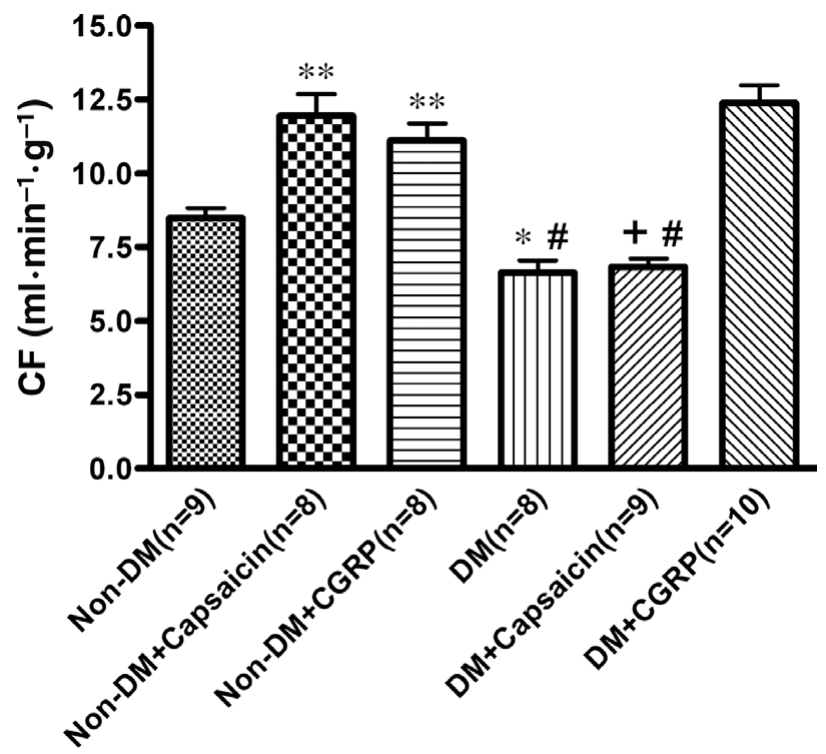

\section{Groups}

Figure 5. Effects of capsaicin pretreatment and calcitonin generelated peptide (CGRP) on the coronary flow (CF) of the diabetic hearts at the end of a 40-min reperfusion. The capsaicin did not increase the $\mathrm{CF}$ in diabetes mellitus (DM) hearts as it did in non-DM hearts, but the CGRP was able to increase the CF in DM hearts as well as in non-DM hearts. Values are mean $\pm \mathrm{SEM} ; * \mathrm{P}<0.05$, $* * \mathrm{P}<0.01$, compared with the non-DM group. ${ }^{+} \mathrm{P}<0.01$, compared with the non-DM+Capsaicin group. ${ }^{\#} \mathrm{P}<0.01$, compared with the $\mathrm{DM}+\mathrm{CGRP}$ group. 
the DM hearts was significantly higher than that from the non-DM hearts $(\mathrm{P}<0.01)$, which is suggestive of the more severe myocardial injury in the DM hearts than that in the non-DM hearts. The pretreatment with capsaicin could significantly decrease the concentration of LDH released from the non-DM hearts in comparison with the untreated ones $(\mathrm{P}<0.01)$, but it failed to demonstrate the same effect in the DM hearts. In contrast, the pretreatment with CGRP was able to attenuate the release of LDH significantly in both the non-DM hearts and the DM hearts $(\mathrm{P}<0.05)($ Figure 6). Taken together, exogenous capsaicin did not attenuate the myocardial injury during the ischemic/reperfusion in the DM hearts, while exogenous CGRP retained this ability.

\section{Discussion}

It is predicted that the number of the patients afflicted by DM will double from 171 million in 2000 to 366 million in $2030 !^{18} \mathrm{DM}$ is regarded as one of the most important risk factors and prognostic risks of coronary heart disease ${ }^{19}$ greatly compromising the quality of life and life expectancy of humans. Diabetic neuropathy, the common complication of diabetes, usually involves the degeneration of the sensory nerve fibers as evidenced in both diabetic animals and patients ${ }^{3-5}$ Acting as an integrator of noxious stimuli, including heat, acid, pollutants, and endogenous pro-inflammatory substances ${ }^{20} \mathrm{TRPV} 1$ is found to be expressed in the sensory nerves, which innervate a variety of tissues and organs such as the brain, spinal cord, skin, gastrointestinal tract, bladder, and cardiovascular system, $6,20,21 \mathrm{DM}$ might interfere with the expression of TRPV1 as several investigations have found that the expression of TRPV1 in DRG and epineurial arterioles was decreased in diabetic animals, 10 In the previous and present study, we disclosed in each that the expression of both TRPV1 and CGRP in diabetic mouse hearts is markedly reduced in comparison with that in the non-diabetic hearts, implying that the function of TRPV1 in the heart was impaired by diabetes.

Many researches have showed that TRPV1 could play an important role of cardioprotection in ischemia/reperfusion injury 13,22 Our previous study found that the mice with TRPV1 gene knockout were more vulnerable to ischemic injury 15 These results demonstrated the importance of TRPV1 in the protection of the heart against postischemic injury. Normally, myocardial ischemia can activate TRPV1 via the decrease of the $\mathrm{pH}$, the increase of blood vessel tension, the high level of regional endothelin and other endogenous agonists such as anandamide and $\mathrm{N}$-acylethanolamines during the ischemia ${ }^{23-26}$ Capsaicin, an exogenous agonist of TRPV1, is able to activate TRPV1 so as to cause the release of neurotransmitters such as CGRP from the sensory nerve fibers and trigger a cascade of cardiovascular responses. Capsaicin is usually believed to be a reflection of the expression of TRPV1,17 which was confirmed by our present study. Interestingly, we found that capsaicin could not improve the cardiac function in diabetic hearts after the ischemia/reperfusion injury, which could be partially because of the depressed number and function of TRPV1 in the diabetic hearts, leading to the failure of the capsaicin action on TRPV1, the worse tolerance of the DM hearts to the ischemia/reperfusion, and subsequently the poor postischemic recovery of cardiac function.

In the present study, we have demonstrated that the cardiac function of diabetic hearts deteriorated more severely after ischemic abuse than that of non-diabetic hearts. Cor-

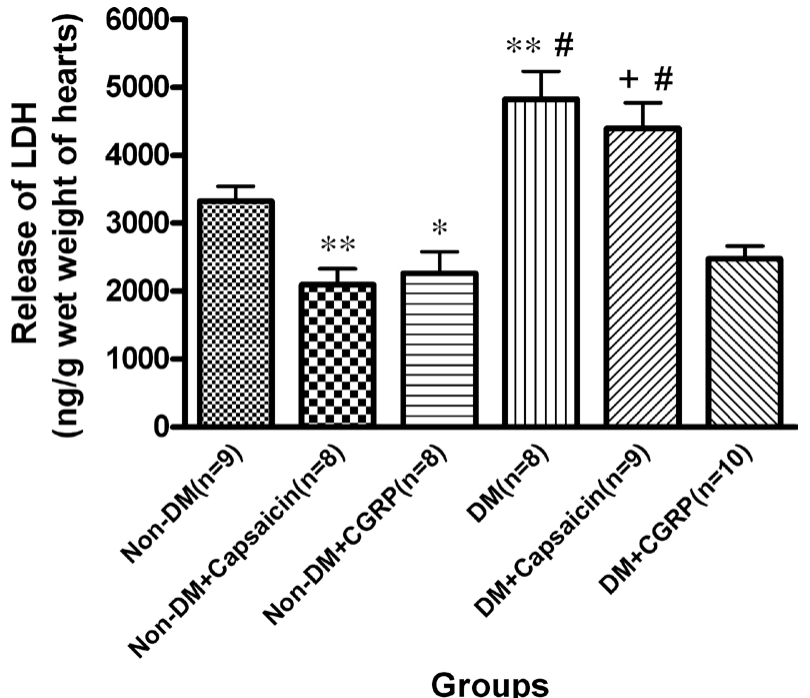

Figure 6. Effects of capsaicin pretreatment and calcitonin generelated peptide (CGRP) on the lactate dehydrogenase (LDH) in the effluents of the whole 40-min reperfusion. The capsaicin could not attenuate the myocardial injury in diabetes mellitus (DM) hearts as it did normally in non-DM hearts, whereas the CGRP was able to attenuate the myocardial injury in DM and non-DM hearts. Values are mean $\pm \mathrm{SEM} ; * \mathrm{P}<0.05, * * \mathrm{P}<0.01$, compared with the non-DM group. $+\mathrm{P}<0.01$, compared with the non-DM+Capsaicin group. ${ }^{\mathrm{P}}<0.01$, compared with the DM+CGRP group.

respondingly, the diabetic patients are also prone to more severe coronary stenosis and cardiovascular events after myocardial ischemia according the data from past clinical studies ${ }^{27-29}$ The linkage of the high morbidity and mortality of coronary heart disease with diabetes is evident but not well understood for its mechanism. Based on the present study, we formulate a possible theory for the susceptibility of the diabetic hearts to ischemic injury, which is that the damage of sensory nerve fibers induced by diabetes causes the decline in the expression and function of TRPV1, and the latter results in the deterioration of cardiac sensory function and consequently the failure of the perception of noxious signals, eventually rendering the diabetic hearts vulnerable to the ischemic injury? 0

As is mentioned above, TRPV1 is closely related with CGRP as CGRP coexists in the TRPV1-positive sensory nerves in the hearts of rats, pigs, and human.31 The activation of TRPV1 results in the release of CGRP, which in turn exerts cardioprotective effects ${ }^{32,33}$ It has been known that CGRP is able to increase the coronary flow via the potent vasodilation, by which it enhances the cardiac function while some other unknown mechanisms are to be investigated. The present study also demonstrated that exogenous CGRP could improve the postischemic recovery of cardiac function and attenuate the myocardial injury in the normal hearts. Unfortunately, the expression of CGRP can be impaired by diabetes as the decreased level of CGRP was detected in the diabetic hearts of current study as well as in our previous study. Encouragingly, the pretreatment of exogenous CGRP was able to improve the postischemic recovery of cardiac function and attenuate the myocardial injury in the diabetic hearts. Therefore, it could be inferred that the downstream pathway of the CGRP where CGRP takes action was not disrupted by diabetes, despite the reduced expression of TRPV1. 
Through the current study, we obtained an insight into the relationship between the postischemic injury of diabetic hearts and the alteration of TRPV1 expression, namely, the impaired expression of TRPV1 in the diabetic hearts is related to the poor recovery of cardiac function and more severe myocardial injury after ischemic abuse. The finding in the current study might shed light on the mechanism of the susceptibility of the diabetic hearts to myocardial ischemia injury and guide future therapy.

\section{Study Limitations}

The present study also had a limitation, however. Immunohistochemistry could definitely help demonstrate the distribution of TRPV1 and CGRP. Comparison of the distribution of TRPV1 and CGRP between the 2 groups would probably make the investigation more persuasive and detailed. But it was a pity that we were not able to carry out the immunohistochemistry because of the limitations of our lab conditions. Therefore, we just identified the difference of the expression of the TRPV1 protein and CGRP between $\mathrm{DM}$ and non-DM hearts.

\section{Acknowledgments}

This study was supported by the National Natural Science Foundation of China (No.30801213), the Planned Science and Technology Projects of Zhejiang Province (No. 2006C33010 and No. 2008R10023), Health Bureau of Zhejiang Province (No.2006QN010) and Collaborative Projects of Zhejiang Province and Ministry of Health (No. WKJ2008-2-019).

\section{References}

1. Wichi R, Malfitano C, Rosa K, De Souza SB, Salemi V, Mostarda C, et al. Noninvasive and invasive evaluation of cardiac dysfunction in experimental diabetes in rodents. Cardiovasc Diabetol 2007; 6: 14.

2. Takenaka K, Sakamoto T, Amano K, Oku J, Fujinami K, Murakami T, et al. Left ventricular filling determined by Doppler echocardiography in diabetes mellitus. Am J Cardiol 1988; 61: 1140-1143.

3. Pittenger GL, Ray M, Burcus NI, McNulty P, Basta B, Vinik AI. Intraepidermal nerve fibers are indicators of small-fiber neuropathy in both diabetic and nondiabetic patients. Diabetes Care 2004; 27: 1974-1979.

4. Schmidt RE, Plurad SB. Ultrastructural and biochemical characterization of autonomic neuropathy in rats with chronic streptozotocin diabetes. J Neuropathol Exp Neurol 1986; 45: 525-544.

5. Faerman I, Faccio E, Milei J, Nunez R, Jadzinsky M, Fox D, et al. Autonomic neuropathy and painless myocardial infarction in diabetic patients: Histologic evidence of their relationship. Diabetes 1977; 26: $1147-1158$

6. Sanchez JF, Krause JE, Cortright DN. The distribution and regulation of vanilloid receptor VR1 and VR1 5' splice variant RNA expression in rat. Neuroscience 2001; 107: 373-381.

7. Caterina MJ, Leffler A, Malmberg AB, Martin WJ, Trafton J, PetersenZeitz KR, et al. Impaired nociception and pain sensation in mice lacking the capsaicin receptor. Science 2000; 288: 306-313.

8. Caterina MJ, Schumacher MA, Tominaga M, Rosen TA, Levine JD, Julius D. The capsaicin receptor: A heat-activated ion channel in the pain pathway. Nature 1997; 389: 816-824.

9. Razavi R, Chan Y, Afifiyan FN, Liu XJ, Wan X, Yantha J, et al. TRPV1+ sensory neurons control beta cell stress and islet inflammation in autoimmune diabetes. Cell 2006; 127: 1123-1135.

10. Davidson EP, Coppey LJ, Yorek MA. Activity and expression of the vanilloid receptor 1 (TRPV1) is altered by long-term diabetes in epineurial arterioles of the rat sciatic nerve. Diabetes Metab Res Rev 2006; 22: 211-219.

11. Zahner MR, Li DP, Chen SR, Pan HL. Cardiac vanilloid receptor 1 -expressing afferent nerves and their role in the cardiogenic sympa- thetic reflex in rats. J Physiol 2003; 551: 515-523.

12. Song JX, Wang LH, Yao L, Xu C, Wei ZH, Zheng LR. Impaired transient receptor potential vanilloid 1 in streptozotocin-induced diabetic hearts. Int J Cardiol 2008 [Epub ahead of print].

13. Pan HL, Chen SR. Sensing tissue ischemia: Another new function for capsaicin receptors? Circulation 2004; 110: 1826-1831.

14. Rang WQ, Du YH, Hu CP, Ye F, Xu KP, Peng J, et al. Protective effects of evodiamine on myocardial ischemia-reperfusion injury in rats. Planta Medica 2004; 70: $1140-1143$.

15. Wang L, Wang DH. TRPV1 gene knockout impairs postischemic recovery in isolated perfused heart in mice. Circulation 2005; 112: 3617-3623.

16. Wang DH, Zhao Y. Increased salt sensitivity induced by impairment of sensory nerves: Is nephropathy the cause? J Hypertens 2003; 21: 403-409.

17. Hoover DB. Effects of capsaicin on release of substance P-like immunoreactivity and physiological parameters in isolated perfused guinea-pig heart. Eur J Pharmacol 1987; 141: 489-492.

18. Wild S, Roglic G, Green A, Sicree R, King H. Global prevalence of diabetes: Estimates for the year 2000 and projections for 2030. Diabetes Care 2004; 27: 1047-1053.

19. Shiba N, Nochioka K, Kohno H, Matsuki M, Takahashi J, Tada T, et al. Emerging problems of heart failure practice in Japanese women. Circ J 2008; 72: 2009-2014.

20. Szallasi A, Blumberg PM. Vanilloid (Capsaicin) receptors and mechanisms. Pharmacol Rev 1999; 51: 159-212.

21. Gulbenkian S, Barroso CP, Cunha e Sá M, Edvinsson L. The peptidergic innervation of human coronary and cerebral vessels. Ital $J$ Anat Embryol 1995; 100(Suppl 1): 317-327.

22. Hu CP, Xiao L, Deng HW, Li YJ. The cardioprotection of rutaecarpine is mediated by endogenous calcitonin related-gene peptide through activation of vanilloid receptors in guinea-pig hearts. Planta Medica 2002; 68: 705-709.

23. Ichihara K, Morimoto T, Shiba T, Tsujitani M, Abiko Y. Attenuation of ischemia-induced regional myocardial acidosis by LP-805, a newly developed vasodilator, in dogs. Eur J Pharmacol 1991; 204: 127-133.

24. Holzer P. Local effector functions of capsaicin-sensitive sensory nerve endings: Involvement of tachykinins, calcitonin gene-related peptide and other neuropeptides. Neuroscience 1988; 24: 739-768.

25. Dymshitz J, Vasko MR. Endothelin-1 enhances capsaicin-induced peptide release and cGMP accumulation in cultures of rat sensory neurons. Neurosci Lett 1994; 167: 128-132.

26. Epps DE, Mandel F, Schwartz A. The alteration of rabbit skeletal sarcoplasmic reticulum function by $\mathrm{N}$-acylethanolamine, a lipid associated with myocardial infarction. Cell Calcium 1982; 3: 531 543.

27. Melidonis A, Dimopoulos V, Lempidakis E, Hatzissavas J, Kouvaras $\mathrm{G}$, Stefanidis A, et al. Angiographic study of coronary artery disease in diabetic patients in comparison with nondiabetic patients. Angiology 1999; 50: $997-1006$

28. Forssas EH, Keskimaki IT, Reunanen AR, Koskinen SV. Coronary heart disease among diabetic and nondiabetic people-socioeconomic differences in incidence, prognosis and mortality. $J$ Diabetes Complications 2008; 22: 10-17.

29. Nakamura Y, Saitoh S, Takagi S, Ohnishi H, Chiba Y, Kato N, et al. Impact of abnormal glucose tolerance, hypertension and other risk factors on coronary artery disease. Circ J 2007; 71: 20-25.

30. Ieda M, Kanazawa H, Ieda Y, Kimura K, Matsumura K, Tomita Y, et al. Nerve growth factor is critical for cardiac sensory innervation and rescues neuropathy in diabetic hearts. Circulation 2006; 114: 2351 2363.

31. Wimalawansa SJ. Calcitonin gene-related peptide and its receptors: Molecular genetics, physiology, pathophysiology, and therapeutic potentials. Endocr Rev 1996; 17: $533-585$.

32. Brain SD, Williams TJ, Tippins JR, Morris HR, MacIntyre I. Calcitonin gene-related peptide is a potent vasodilator. Nature 1985; 313: $54-56$.

33. Li YJ, Xiao ZS, Peng CF, Deng HW. Calcitonin gene-related peptideinduced preconditioning protects against ischemia-reperfusion injury in isolated rat hearts. Eur J Pharmacol 1996; 311: 163-167. 